\title{
SEMANTIC CONSTRAINTS ON THE CAUSED-MOTION CONSTRUCTION
}

\author{
ALBA LUZONDO OYÓN \\ Universidad de La Rioja \\ alba.luzondo@gmail.com
}

\begin{abstract}
Within the field of Cognitive Linguistics, Goldberg's (1995) approach to Construction Grammar offers a detailed analysis on the semantic constraints that affect the caused-motion construction. The present paper aims to revise one specific constraint which Goldberg tentatively states as follows: «if the action denoted by the verb implies an effect other than motion, then a path of motion cannot be specified» (1995:170). In doing so, we will study the behavior of some «contact-by-impact» verbs (i.e., slap, smack, whack, knock and hit) making use of the analytical tools provided by the Lexical-Constructional Model (LCM), developed by Ruiz de Mendoza and Mairal (2007).
\end{abstract}

KEY WORDS: caused-motion construction, Lexical-Constructional Model (LCM), semantic constraints, lexical-constructional subsumption, contact-by-impact verbs.

\section{RESUMEN}

En el campo de la Lingüística Cognitiva, Goldberg (1995), en su acercamiento a la Gramática de Construcciones ofrece un análisis detallado de las restricciones semánticas que afectan a la construcción de movimiento causado. El presente artículo se propone revisar una de las restricciones tentativamente propuestas por Goldberg: «si la acción denotada por el verbo implica un efecto que no sea movimiento, entonces la trayectoria no puede ser especificada» (1995:170). De este modo, estudiaremos el comportamiento 
de algunos verbos de contacto-por-impacto haciendo uso de las herramientas analíticas proporcionadas por el Modelo Léxico-Construccional (MLC) desarrollado por Ruiz de Mendoza y Mairal (2007).

PALABRAS CLAVE: construcción de movimiento causado; restricciones semánticas; Modelo Léxico-Construccional (MLC); subsunción léxico-construccional; verbos de contacto por impacto.

\section{INTRODUCTION}

The caused-motion construction has been extensively studied in Cognitive Linguistics. Goldberg $(1995,2005)$ has devoted considerable space to it in her proposals on Construction Grammar. The basic semantic structure of the construction specifies an argument role that causes the theme argument to move along a path designated by a directional prepositional phrase (X CAUSES Y TO MOVE Z). Goldberg (1995) presents five generalizations in relation to the semantic constraints that affect the caused-motion construction. The constraints variously deal with the kinds of situation that can be encoded by the construction. For example, it is observed that the theme argument does not make a cognitive decision in relation to movement (e.g. They frightened/*persuaded her out of the house). The theme entity is further presumed to move into the specified location (e.g. Sam asked/*begged John into the room) and non-direct conventional causation is admitted by the construction (e.g. Her new boss flew her to Madrid for a Conference, where in actual fact it was the air carrier that did the action).

In this research context, the present paper aims first to revise and improve one specific constrain that Goldberg (1995: 170) tentatively states as follows: «if the action denoted by the verb implies an effect other than motion, then a path of motion cannot be specified». To illustrate this constraint, Goldberg follows Jackendoff (1990) in making a distinction between verbs that pattern like hit and those that pattern like strike: He hit ${ }^{*}$ struck the ball across the field. 'Strike' verbs (e.g. assault, sock, spank, slash) require the impacted entity to be affected in a way that does not involve motion. 'Hit' verbs (e.g. slap, smack, whack, knock), in contrast, would seem to allow the impacted entity to be or not to be affected. However, corpus evidence is not consistent with this purported usage pattern: Eight times he struck the ball out of the playing area, a feat worth six runs; Dunivant struck the ball across the face of the Norway goal; Amber McKenna socked the ball into the field; Zorakun dashed at Mikonu and slashed him into the air, jumped, avoided his magic attack and slashed him back down. In view of the evidence, we need an alternative hypothesis that deals with the data in a more accurate way. We will do so by making use of the analytical tools provided by the Lexical Constructional Model (LCM), as proposed in Mairal and Ruiz de Mendoza (2007) and Ruiz de Mendoza and Mairal (2007). One of the central areas of study of the LCM is the study of how lexical and constructional structure interact in a principled way. The model distinguishes a number of licensing and blocking factors on what its proponents have called lexical-constructional subsumption, i.e. the constrained incorporation of lower-level configurations into higherlevel configurations. 
The second aim, which is related to the first, is to analyze some of the «contact-byimpact» verbs (slap, smack, whack, hit, knock) in the line of Goldberg's theory in order to achieve a more refined explanation. We will do so on the basis of the application of the LCM approach to semantic constrains. As a consequence of this analysis, we shall propose a continuum amongst these verbs that will account for their idiosyncratic differences in a way that, as we will contend, endows the existing analysis with greater descriptive elegance and consequently more explanatory power.

\section{AN OVERVIEW OF THE LEXICAL CONSTRUCTIONAL MODEL}

The Lexical Constructional Model is a recent approach to meaning construction developed by Ruiz de Mendoza and Mairal (1997ab) with a view to making productive connections between projectionist and constructional approaches to the relationship between lexicon and grammar. In general, the projectionist view (e.g. Dik, 1997; Pustejovsky, 1991; Van Valin, 2005) postulates that syntax is motivated by the semantic configuration of the predicate-argument structure of lexical items. The constructionist view postulates the existence of more abstract and independent argumental configurations, of a semantic nature, into which lexical items are incorporated. Thus, the verb kill, which is transitive, in a projectionist account would be described as matching semantic role structure and syntactic configuration in terms of mapping the Agent-Predicate-Patient thematic configuration to the Subject-Verb-Object syntax. In a constructionist account, the same verb would be argued to unify its structure, at the semantic level, with the general structure of the transitive construction, which has slots for agent-type and objecttype argumental roles, whether these are prototypical agents or not. In this way, «I saw the cat» is a less prototypical case of transitive structure than «I killed the cat» (where the object is a truly affected entity) by virtue of the lexical predicate experiencing some sort of adaptation that allows it to fuse into the transitive construction. This is an advantage of the constructional approach over the standard projectionist accounts, especially because it allows us to determine the conditions under which a given lexical item may or may not participate in a given construction. For example, in The speaker addressed the audience with a few remarks, the verb «address» can form part of a transitive construction even if the speaker is not a prototypical agent (it is rather a communicator) and the remarks are not a prototypical instrument (cf. He killed the cat with a knife, where «knife» is a prototypical instrument). The verb «address» can also occur in an alternative construction: The speaker addressed a few remarks to the audience, which has been called the causedmotion construction (Goldberg, 1995, 2005), with roughly the same meaning, but a number of different implications (in the caused-motion configuration the receiver of the message is not seen as if it were an affected entity, unlike in the transitive, but as the physical destination of the speaker's activity). In spite of this clear explanatory advantage, constructional models have one weakness when compared with projectionist theories in that the latter incorporate into their specifications indicators of syntactic projection that create the conditions to make the semantics-syntax mapping fairly straightforward. This is usually done on the basis of a logical structure specification based on Aktionsart distinctions like the ones proposed in Van Valin (2005). The logical structure decomposes 
the lexical item into primitives that are bound to argumental variables. However, the logical structure descriptions are insufficient to explain why a given predicate can take part in many constructions, which results in the unnecessary proliferation of senses for lexical entries (with the consequent loss in explanatory elegance). Such descriptions provide little semantic information on the lexical items, which makes these models inadequate from the point of view of accounting for the full range of meaning implications of lexical items.

The Lexical Constructional Model integrates insights from the constructional and projectionist approaches in two ways: (1) it has developed a formalism for lexical description in the form of lexical templates, which contains not only logical form representations in preparedness for syntactic projection, but also a systematic semantic structure description with elements of world knowledge captured in the form of amalgams of semantic primes and lexical functions; the semantic and logical structures work on internally bound sets of variables; (2) it has developed a similar formalism for constructional descriptions and sets of constraints on the lexical-constructional fusion process; some of these constraints are internal (they deal with the compatibility between lexical and constructional specifications) and some others are external (they allow us to see features of some configurations as if they were features of a different kind that can be adapted to constructional requirements). To give an example, consider again the sentence: The speaker addressed a few remarks to the audience. The verb «address» is not a caused-motion verb and it does not typically take the message as a complement. So this would create an important internal mismatch between the semantics of the verb and the semantics of the construction. However, it is possible to adapt this verb into the causedmotion construction simply because it is possible to see a non-caused-motion predicate as if it were so provided that we can see the speaker as a doer of the action and the object as some for of «effectee».

\section{EXTERNAL CONSTRAINTS ON LEXICAL-CONSTRUCTIONAL SUBSUMPTION.}

Before devoting ourselves to the close study of the «contact-by-impact» verbs presented by Goldberg (1995: 170), let us first deal with some of the external constrains on lexical-constructional subsumption, which will be analyzed within the scope of the Lexical Constructional Model (LCM). Constructional subsumption has been defined by Ruiz de Mendoza and Mairal (2007) as a cognitive process whereby core grammar (i.e. lower-level) representations are incorporated into other higher-level (i.e. pragmatic or discourse) configurations, thus yielding conceptual representation at these levels. Consider the following sentences:

(1) The audience laughed the actor off the stage.

(2) Kelly talked me into it.

(3) He drank himself into a stupor.

These three examples are based on high-level metaphors. Example (1) makes use of the AN EXPERIENTIAL ACTION IS AN EFFECTUAL ACTION metaphor. Example 
(2) is based on the metaphor A COMMUNICATIVE ACTION IS AN EFFECTUAL ACTION; and (3) is referred to as AN ACTIVITY IS AN (EFFECTUAL) ACCOMPLISHMENT (Ruiz de Mendoza and Mairal 2007a; Ruiz de Mendoza 2007). When considering sentence (1) we may wonder why is it possible to convert «laugh (at)» into «laugh»? According to Ruiz de Mendoza and Mairal, the constructional requirement is to find a causative accomplishment predicate that will initiate the causal chain that results in the object of the action moving from one location to another. Since «laugh» is an activity predicate, without any causal and resultative component, the only way to make it part of the caused-motion construction is by reinterpreting the activity predicate as if it were a causative accomplishment predicate. Consequently, thanks to subcategorial conversion, a verb such as «laugh» can be subsumed into a higher-level configuration through the use of a metaphor (EXPERIENTIAL ACTION IS EFFECTUAL ACTION), acquiring a new «idiosyncrasy» that has a direct effect on the receiver in such a way that this receiver or effectee will move along a designated path. In words of Ruiz de Mendoza and Mairal, sentence (2), as mentioned before, is based on the metaphor COMMUNICATIVE ACTION IS EFFECTUAL ACTION, which again licenses a subcategorial conversion process whereby the receiver of the message is seen as if directly affected by the action of talking rather than as a goal of the message. Finally, the metaphor on the third example allows us to interpret the originally intransitive predicate «drink» in terms of a transitive structure of the actor-object kind.

We have just seen how the LCM addresses the activity of external constrains on the fusion of some verbal predicates into the caused-motion construction. Before applying this proposal to the set of verbs proposed by Goldberg in order to see whether the caused-motion construction licenses their use or blocks them out, we first need to take a look at the internal constrains on lexical-constructional subsumption. Once we have studied both internal and external constrains, we shall discuss Goldberg's analysis on «contact-by-impact» verbs.

\section{INTERNAL CONSTRAINTS ON LEXICAL-CONSTRUCTIONAL SUBSUMPTION}

Ruiz de Mendoza and Mairal state that lexical-constructional subsumption is also regulated by constrains that make reference to the internal semantic make-up of the lexical and constructional templates. Internal constrains on subsumption intend to specify all the conditions under which a lexical template may modify its internal configuration. Thus, they take the form of licensing or blocking factors that depend on lexical class ascription, lexical-constructional compatibility, and either predicate or internal variable conditioning of external variables.

The Lexical-Constructional Model has identified a number of internal constraints named: full matching, variable suppression, internal variable fusion, lexical class constraint, subevent identification constraint, lexical blocking, predicate-argument conditioning and internal variable conditioning. We will primarily focus on predicate-argument conditioning since not only is it crucial to the understanding of how «contact-by-impact» verbs behave, but it will also be our key to discuss Goldberg's proposal on the affectedness of the entity receiving the impact. 
As Ruiz de Mendoza has noticed, sometimes a lexical template can place restrictions on the kind of instantiating element that we can have for a constructional argument. The constructional structure of the caused-motion construction could be paraphrased as $X$ pred- $Y(=N P)-Z(=P P)$. In principle, the constructional template can take any verb participant role to instantiate the $\mathrm{Y}$ element, which can be either human or non-human (e.g. Jaime pushed Erin into the car; The sun slashed its way into the room). However, once the predicate and PP slots have been filled in, this choice constrains the kind of Y element that we can have. For example, in Anna loved me back into life, the Y element has been realized by a human verb role. It would be infelicitous to say that *Anna loved a chair back into live. A similar phenomenon could be found in Spanish. The sentence Ricardo le propinó un bofetada en la cara (lit. 'Richard gave a smack to his face', 'Richard smacked his face') is possible, whereas it would seem awkward to say *Ricardo le pegó un bofetada a la pared (lit. 'Richard gave a smack to the wall', ''Richard smacked the wall') since the nature of «pegar una bofetada» ('smack someone's face') requires a human Y element, and the PP «a la pared» ('to the wall'), once chosen, constrains the type of argument that we can select (e.g. Le pegó un golpel un puñetazo a la pared 'He hit the wall with his fist'). In this line of thinking, predicate-argument conditioning applied to the aforementioned verbs appears to be strongly related to the caused-motion construction as data reveals, having their Y element usually realized as a human entity rather than an object (Sharon slapped them out of the government, I have finally smacked myself out of denial, The Obama phenomenon quickly knocked her out of her complacency). Goldberg stated that verbs of the hit-class allow their direct objects to be unaffected or unaffected except for the particular effect of motion (1995:170). However, once again corpus data shows that the $\mathrm{Y}$ element is indeed affected by the particular effect produced by the predicate when subsumed into the caused-motion construction. Therefore, we may understand the direct object to receive the impact denoted by the verbal predicate, and by being unable to absorb the impact, to be forced to move along a designated path.

Another interesting idea is both related to the semantic nature of the verb and the election of the PP, which «symbiotically» constrain one another. That is to say, on the one hand, the selection of a verbal predicate is determined or constrained according to the prepositional phrase we have chosen. On the other hand, the semantic nature of the verb may license or tend more or less towards motion (once the PP slot has been linguistically realized). To make this point more clear, consider for example the verb slash defined as (http://encarta.msn.com/):

— «Make cuts in something: to make long deep cuts in something».

— «Reduce or cut something short: to reduce or shorten something greatly».

- «(Forestry) Clear growth by cutting: to cut bushes and undergrowth from a wooded area».

The semantic nature of slash refers to an action such as incision, a mainly slight movement within/into something. As a consequence, it is the very semantic nature of the verb that blocks out motion, which focuses more on the action of slashing/cutting than on the rather imperceptible motion caused by it. Notice, however, that when attached to common caused-motion prepositional phrases («out of», «into the», «across the», «off the»), 
slash appears to allow subsumption mainly with «out of» and in specific contexts, thus being perceived as a fictional-caused-movement of entities «out of» a designated place:

(4) Jetta quickly slashed him out of the way, doing what looked like lethal damage to Theodore.

(5) Mr Paul Martin, slashed billions of dollars out of the health care system in our country.

Examples (4) and (5) are based on a force image-schema in which the subject is responsible for a change in the location of the object. That is to say, thanks to subcategorial conversion the predicate acquires an idea of metaphorical motion.

\section{GOLDBERG'S ANALYSIS ON «CONTACT-BY-IMPACT» VERBS}

In this section we will analyze the first group of «contact-by-impact» verbs that pattern with hit as described by Goldberg (1995). Our aim is to study each verb class and its possible applicability to the caused-motion construction, while bearing in mind the possible internal and external constraints on lexical-constructional subsumption.

Goldberg (1995:170), following Jackendoff (1990a), proposes a distinction between two verb classes. On the one hand, we have verbs like slap, smack, whack and knock which pattern like hit, whereas on the other, verbs such as assault, sock, spank, clobber, slash, bludgeon and impact pattern like strike. What distinguishes these two classes of verbs of forceful impact is whether the impacted entity is necessarily affected in a way that does not involve motion (cf. Fillmore 1970). Goldberg (1995:170) argues that all the verbs of the strike-class require that the impacted entity be affected (*With an open hand, the toddler struck the tree. The toddler struck his playmate. *Joe assaulted/bludgeoned/impacted the steel block. The disgruntled player socked the coach). As opposed to them, verbs of the hit-class, which do allow their directional to be specified, allow their direct objects to be either unaffected generally (hit, slap) or unaffected except for the particular effect of motion (knock)», (e.g. Sam hit the table. Sam slapped/smacked the table). In other words, whereas strike-like verbs require the impacted entity to be affected, the direct object of the hit-class can remain unaffected.

However, corpus evidence shows inconsistency with such a proposal. Consider the following cases:

(4) They yanked it out and socked him into the hospital.

(5) Sharon slapped them out of the government.

(6) A worry smacked me out of bed around 4.

(7) When I think of Schiller, I think of this»-touching the Morse Whitman head near which he stood—»rough, crude, struck straight out of Nature, unfinished. (Walt Whitman).

Goldberg's tentative generalization states: «if the action denoted by the verb implies an effect other than motion, then a path of motion cannot be specified». To illustrate this, 
Goldberg considers that *Pat shot Sam across the room is indeed incorrect. Nevertheless, corpus evidence provides many examples such as the following: It made a tremendous noise and shot him across the room. He was wound so tight I could have shot him across the room. The force of the explosion shot her across the room.

Our alternative generalization therefore would be: if the entity affected by the action absorbs the impact and does not move, then caused-motion will not occur. However, if the direct object gets affected in a way that involves motion, caused-motion could be applied. Before continuing with our discussion and for the sake of clarification, we would like to emphasize the fact that while some of these verbs will show a clear inclination towards caused-motion, others will vary depending on the context, sometimes licensing it, some others blocking it out, making it hard to categorize them according to fixed behavioral patterns. The reason why this happens should not be believed to solely lie on the nature of the verb because, contrary to what Goldberg states, such a characteristic is not sufficient to know whether the caused-motion construction could be applied in every single existing context; but it is rather a combination of the nature of the verb plus the external and internal constrains (as proposed by the Lexical-Constructional Model) that truly accounts for their distinctions. In addition, it is hard to fully and/or uniquely consider those verbs according to their semantic nature since dictionary entries show a circular tendency when ascribing meaning to them. For instance, most lexicographic work either offers strike as a synonym of hit and vice-versa or provides similar definitions for both of them, such as «cause to experience suddenly, affect or afflict suddenly, usually adversely». Having a detailed, specific description of the distinctive features that could be found amongst these verbs, would facilitate the understanding of their internal semantic nature.

After a close study of the behavioral patterns of «contact-by-impact» verbs, as we shall see next, it is important to point out that grouping these two verb-classes into fixed categories depending on whether the impacted entity is affected in way that does not involve motion (Goldberg 1995:170) does neither account for their tendency towards caused-motion, nor does it explain the real semantic differences underlying their behavior. Taking into account that in one way or the other, the majority of these verbs allow subsumption into the caused-motion construction, it would be productive to propose a continuum of «contact-by-impact» verbs, with various degrees of categorization from the most prototypical examples to the less recurrent ones. A small graphic will be provided at the end of the present paper.

\section{THE HIT-VERB CLASS: ANALYZING EXAMPLES}

We shall now analyze the hit verb-class (slap, smack, whack, knock), which according to Goldberg does not require an affected entity. In most cases the affected entity should not be human. Many examples will be provided with every relevant prepositional phrased («across the», «into the», «off the», «out of the») in order to cover any possible indication of motion. 


\subsection{SLAP}

(9) She slapped him across the room.

(10) Gieger slapped him across the room with the back of his hand.

(11) They slapped them into the quickest cultural reference.

(12) The 2004 catastrophe slapped some sense into the US officials responsible for its budget.

(13) Erica B. would have slapped him off the stage for that.

(14) I don't think you could have slapped the smile off the concierge's face.

(15) Woolsey, favoring plug-in hybrids, slapped many attendees out of a jargoninduced lull.

(16) If you think this started when we slapped Hussein out of power in Iraq, you'd be wrong.

(17) But it slapped him, it slapped him out of the mundane.

(18) I slapped myself out of my trance.

(19) The functionality and sleek design of this apple product has slapped me out of my normal stupor.

(20) [..] Is unhappy over the loss of her job and has slapped Julie out of frustration.

As corpus evidence reveals, slap seems to be a fairly prototypical example within our continuum, licensing the caused-motion construction with every prepositional phrase selected. Notice too that in the case of the verb we are dealing with, the semantic nature is indeed very revealing, as opposed to some of the verbs within the same class. Intuition already tells us that a verb defined as «hit somebody with an open hand/Strike sharply» (Oxford online dictionary, www.askoxford.com), would most likely accept caused-motion due to the nature of the impact. Further notice that in a way the nature of slap (as well as the case of slash) when applied to a human entity, also constrains the type of PP that we can have. That is to say, most likely we will not find prepositional phrases such as «across the field» due to the obvious impossibility of slapping a person and making the affected direct object move more than a couple of meters from its present location.

In all these cases, the entity that receives the impact is understood to move along a designated path. This is so because the verb slap has suffered a subcategorial conversion process licensed by a high-level metaphor that allows an activity (contact-by-impact) verb like slap to shift to a causative accomplishment predicate which initiates a causal chain that results in the object moving from one location to another.

In relation to predicate-argument conditioning, we can observe that when the predicate and the PP slot have been filled in, the Y element allowed in the construction can be linguistically realized as a human entity approximately $95 \%$ of the times. All these evidences show that Goldberg's analysis concerning the unaffectedness of the direct object is not so, in the case of «slap». If the entity receiving the impact were understood to be unaffected, then caused-motion would not occur.

Moreover, it is worth mentioning that the prepositional phrase «into the» favors the occurrence of concepts like mundane/trance/stupor/frustration but blocks others such as *happiness/joy/poverty. This phenomenon has been explained by the Lexical Constructional Model through an internal constraint labeled internal variable conditioning, which 
arises from the internal configuration of the lexical template instantiating the predicate slot of a constructional template. The internal predicate variables place constraints on the nature of both the predicate and constructional argument. A clear example is supplied by the use of the verb «drive» to instantiate the caused-motion construction. The lexical template of drive contains an indication of loss of control for the object. Because of this, there is a tendency for the $\mathrm{Z}$ element to be axiologically negative and have frequent instantiations such as: desperation, panic, madness, frenzy, depression, apathy, rage, terror, etc. In the same way but less frequently than «drive», «slap» could require a negative $\mathrm{Z}$ element as it could be suggested that in order to get (somebody) out of a difficult, sad situation, a strong impact on the entity suffering such condition would be needed.

Finally, it would be interesting to take a look at the expression «vb. + (some) sense into the», which will appear in many of these examples. Ruiz de Mendoza has analyzed such phenomenon as follows: ««slap» is used to indicate manner in which the action is carried out. So we could find a more basic way of expressing the idea of "causing someone to be reasonable" with a basic caused-motion verb, as in «put some sense into him». If we use «slap» rather than «put» it is because English allows us to conflate motion and manner of motion within the same structural slot of the caused-motion construction.

The interesting thing about using «slap» is that it is not a caused-motion verb (it is a «strike» verb, rather than a «hit» verb) in the standard Goldbergian analysis. However, it is used as a caused-motion verb, probably because it is semantically coerced into that verb-class. This form of coercion is possible through a high-level metaphor whereby the implicit result in «slap» (the way slap affects the object) is seen as caused-motion (another form of result, in fact). So, metaphorically one kind of resultant state (not involving caused-motion) can be seen as another kind of resultant state (involving caused-motion). Another interesting thing is that putting sense into someone is in itself another (low-level) metaphor: we use caused physical motion into a container to talk about causing a certain entity to attain a certain state. The high-level metaphor only affects the provisional reclassification of «slap» in terms of verb class. The low-level metaphor affects the change of state meaning implications».

\subsection{SMACK}

(21) He yelled, released Angel, and smacked Lilah across the room, into the filing cabinets.

(22) She smacked that little monkey across the room.

(23) The Welsh band $60 \mathrm{Ft}$. Dolls smacked themselves into the mid-'90s postgrunge.

(24) Maybe that straight talk smacked some sense into the audience.

(25) I would have smacked the shit out of the Doctor.

(26) That's what the Scriptures state, he called question on God, but if God just smacked him out of existence...

(27) His wife's telltale laughter smacked him out of his dream.

(28) I have finally smacked myself out of denial.

(29) Alexander Fleming's discovery of penicillin chastised many Iranians and 
smacked them out of their state.

(30) This DVD is a fine tribute to a young filmmaker who has smacked the convention out of storytelling.

«smack» is defined as: «to hit somebody with a quick stinging and usually noisy blow with the palm of the hand / hit against something noisily: to strike against, collide with, or land in something with a sharp loud noise» (Encarta online dictionary, www.encarta.msn.com). Although this verb accepts caused-motion, it is interesting to highlight that instances with the verb to «slap» were more recurrent than with «smack». The semantic nature of the verb, along with the internal constraints proposed above that for the sake of abbreviation we should not deal with again, shows that probably caused-motion is less prominent due to the fact that «smack», according to its definition, focuses more on the idea of «noise» (noisy blow, sharp loud noise) produced by the impact that on the impact itself.

\subsection{WHACK}

(31) The school bus whacked them off the road.

(32) He literally whacked activist Abbie Hoffman off the stage.

(33) Meatus picked up his helmet from the table and whacked the poor fellow across the room.

(34) If a certain amount of harmless revelry can be whacked out of Fourth Avenue, we must dash there with the vim of highly-trained smell-dogs.

(35) He is not nearly as nutso as he was when the stuff really whacked him out of his mind.

(36) I wondered if maybe Ms. Skeeter's proboscis had maybe gotten left behind when I whacked her out of this existence.

(37) Blair whacked him into the House of Lords and then just moved him into the cabinet.

It is important to notice that even though «whack» seems to participate in the caused-motion construction, instances like those were not so recurrent, in contrast to what is the case with the other verb cases. We could state that such a verb works with a causative interpretation in certain contexts, but its tendency to appear as a caused-motion verb is fairly scarce. Consequently, we shall consider these examples more as oddities than as consistent patterns. Moreover, «whack» works better with the prepositional phrase «out of», whereas it finds obstacles with «into the», «across the» and «off the». Consequently, once the PP slot has been filled, caused-motion appears as a marginal case.

\subsection{KNOCK}

(38) The voltage knocked her clear across the studio.

(39) Alpha Man knocked Doomlaut across the street and into a nearby building.

(40) It knocked Prydon across the room and left him unconscious. 
(41) At the Glass City 200 in Toledo, Ohio, drivers Don St. Denis and Michael Simko tangled after St. Denis' car knocked Simko's car into the wall.

(42) Patty Torr, a vice president for F.C. Tucker Realtors, said one builder this spring knocked \$100000 off the price of a Northside home.

(43) The Obama phenomenon quickly knocked her out of her complacency.

(44) Jumping slightly as her friend next to her knocked her out of her trance.

(45) This destruction has almost taken place, not because those ideas knocked Christianity out of existence, but because they converted Christianity.

(46) However, a groin injury knocked him out of action for the remainder of the year and part of the next.

(47) He told me that the thing that knocked America out of depression and into a good mood again was the arrival of The Beatles.

The verb to «knock» appears as one of the most prototypical examples, together with SLAP, of all «contact-by-impact» verbs allowing caused-motion.

\subsection{HIT}

(48) And he just really hauled off and hit my dad with a perfect shot - hit him across the room.

(49) When a cyclone hit Moheshkhali off the coast of Bangladesh in April 1991 the effects on the island were devastating

(50) But it isn't until a half-hour later that the first bona fide hit slams into the audience.

(51) I know I can't hit big sixes into the crowd. They will hit themselves into the playoffs (and then hopefully by then they will figure out the pitching situation).

(52) Billy Williams of the Oakland A's hit himself into the record books with his 400th career.

(53) Has Andrew Jones hit himself out of a 200 million dollar contract?

(54) Sidhu arrived at the microphone and proceeded to hit himself out of trouble with a rapid-fire sequence of proverbs and epigrams.

(55) Maybe it's because they now feel confident enough to literally hit themselves out of any misfortune.

It is important to notice that even though examples with the verb to hit have been offered, caused-motion is by far not so recurrent. Surprisingly, a very similar situation is to be found with the predicate strike. The following are some scarce instantiations of the abovementioned verb:

(56) We should lose something besides a poetic effect if for that reason we struck her out of the account.

(57) But in 1968, angry at his wife's alleged infidelity, he struck her out of the will and made his father the sole beneficiary.

(58) Instead, Pirates struck themselves out of trouble and with high spirits began the 11 th inning. 
Neither hit nor strike license caused-motion in most contexts, even having been originally categorized as the most prototypical, general examples of «contact-by-impact» verbs. We should assume, therefore, that the caused-motion construction generally functions better with those verbs that specify manner of motion (slap, knock). Furthermore, another very plausible consequence of our first observation is that it is indeed the fact that hit and strike are basic level categories of «contact-by-impact» verbs, which causes caused-motion to be usually blocked out. In other words, the caused-motion construction requires in its most prototypical, enriched form: a) a causer of motion, b) an object that receives the impact, c) motion, d) manner of causing motion, e) manner of motion, and f) an instrument; thus, the more specific the predicate is, the easier the subsumption process into the caused-motion construction.

Consider the following well-known examples: 1) He hammered the nail into the wall is most likely to be chosen than 2) ?He hit the nail into the wall, just because the former predicate specifies manner and instrument in which the $\mathrm{Y}$ element receives the impact. Hit and strike, as opposed to hammer, being basic level category verbs, and consequently, less sensitive to constructional parametrization, will most likely be avoided in their use when involving caused-motion. In sum, the less we parametrize a constructional slot when selecting a «contact-by-impact» predicate, the fewer the instances of caused-motion that we will find.

\section{CONSIDERING A LAST EXAMPLE: «PAT SHOT SAM ACROSS THE ROOM»}

Before concluding the present paper, let us deal, for the sake of clarification, with the «shoot» case pointed out by Goldberg, in order to make our statement clearer. Consider these two instances provided by Goldberg (1995:170):

a) Pat shot Sam.

b) Pat shot the bullet.

According to this linguist, the verb «to shoot» allows either the impacted entity (a) or the trajectory as direct object (b). Goldberg claims: «when a path argument is present, the direct object can only be interpreted as trajectory; it cannot be viewed simultaneously as trajectory and impacted entity». In this line of thinking, *Pat shot Sam across the room (Goldberg 1995:170) is incorrect because in her words, «if the bullet is understood to penetrate Sam, then Sam is necessarily affected in a way that does not involve motion, and so a path of motion cannot be specified». Interestingly enough, we have already seen that this example is possible in English. Therefore, we can indeed interpret that the bullet that impacted on Sam caused him to move across the room. That is to say, it is not so much that we view it simultaneously as a trajectory and an impacted entity, but as the fact that the trajectory is the consequence of the way in which the entity is impacted (in other words, the shot forces Sam across the room due to the probably intense impact received). Notice however that if a resultative effect is specified through an explicature, *Pat shot Sam dead across the room, then path cannot be present. We may refine Goldberg's tentative generalization (when applied to such verb) as follows: «When the action denoted by the verb implies an effect other than motion, a path cannot be specified if the non-motion effect has been made explicit». It would be incongruent to try to apply motion to an already specified non-motion state (dead). 


\section{ConClusion}

As we have seen along the present paper the hit verb-class licenses subsumption into the caused-motion construction in different degrees. It is not so much a matter of considering if the impacted entity is necessarily affected in a way that does not involve motion (Goldberg 1995:170), but rather of whether the nature of the verb along with the different constraints proposed, licenses or blocks out motion. Offering a continuum concerning various category levels on subsumption, would account for a more elegant way of classifying «contact-by-impact» verbs:

\section{+ prototypical}

- prototypical

$\begin{array}{r}\text { knock/slap } \quad \text { hit/strike/whack } \\ \hline\end{array}$

Contact-by-impact verbs continuum

\section{REFERENCES}

GoldBerg, Adele E. (1995), Constructions: A Construction Grammar Approach to Argument Structure. Chicago: University of Chicago Press.

-, (2005), Constructions at work: the nature of generalization in language. Oxford: Oxford University Press.

JACKENDOFF, R. (1990), Semantic Structures. Cambridge, Mass.: MIT Press.

-, (1990a), On Larson's treatment of double object construction. Linguistic Inquiry 21, 427-456.

MAIRAL UsÓN, Ricardo \& RUIZ DE MENDOZA, Francisco (2006) Internal and external constraints in meaning construction: the lexicon-grammar continuum». Estudios de Filología Inglesa: Homenaje a la Dra. Asunción Alba Pelayo. Madrid: UNED.

Pustejovsky, James (1991), The Generative Lexicon. Cambridge, Mass.: MIT Press.

Ruiz de Mendoza, Francisco J. \& Mairal Usón, Ricardo (2006), Grounding lexical and constructional meaning in metaphor and metonymy. Paper presented at the IV Internacional Conference on Construction Grammar. University of Tokyo.

-, (2007a), High-level metaphor and metonymy in meaning construction. In Günter Radden, Klaus-Michael Köpcke, Thomas Berg \& Peter Siemund. (eds.) Aspects of Meaning Construction in Lexicon and Grammar. Ámsterdam/Philadelphia: John Benjamins; 33-49.

-, (2007b), Levels of semantic representation: where lexicon and grammar meet, Interlingüística, 17.

RUIZ DE MENDOZA, Francisco J. (2007), High level cognitive models: in search of a unified framework for inferential and grammatical behavior. In Perspectives on Metonymy, Kosecki, Krzysztof (ed.), Frankfurt/Main: Peter Lang, 11-30.

VAN VALIN, Robert D. Jr. (2005), The syntax-semantic-pragmatics interface: an introduction to Role Reference Grammar, Cambridge: Cambridge University Press. 